\title{
Regulatory T-cell development in the human thymus
}

\author{
Íris Caramalho ${ }^{\dagger}$, Helena Nunes-Cabaço ${ }^{\dagger}$, Russell B. Foxall and Ana E. Sousa * \\ Instituto de Medicina Molecular, Faculdade de Medicina, Universidade de Lisboa, Lisbon, Portugal
}

The thymus generates a lineage-committed subset of regulatory T-cells (Tregs), best identified by the expression of the transcription factor FOXP3. The development of thymus-derived Tregs is known to require high-avidity interaction with MHC-self peptides leading to the generation of self-reactive Tregs fundamental for the maintenance of self-tolerance. Notwithstanding their crucial role in the control of immune responses, human thymic Treg differentiation remains poorly understood. In this mini-review, we will focus on the developmental stages at which Treg lineage commitment occurs, and their spatial localization in the human thymus, reviewing the molecular requirements, including T-cell receptor and cytokine signaling, as well as the cellular interactions involved. An overview of the impact of described thymic defects on the Treg compartment will be provided, illustrating the importance of these in vivo models to investigate human Treg development.

Keywords: human thymus, regulatory T-cells, FOXP3, regulatory T-cell development, human thymic defects, primary immunodeficiency

\section{Introduction}

Regulatory T-cells (Tregs) play a major role in immune homeostasis by preventing or limiting T-cell activation, particularly in the context of auto-antigens. Expression of the transcription factor forkhead box P3 (FOXP3), considered a master regulator of Treg development and function, is essential for their role in the maintenance of dominant tolerance [reviewed in Ref. (1)]. Conditions where FOXP3 is defective or absent, such as the recessive disorder immune dysregulation, polyendocrinopathy, enteropathy, X-linked (IPEX) syndrome, are characterized by aggressive autoimmune manifestations that are usually fatal within the first 2 years of life, unless corrected via hematopoietic stem-cell transplantation (2-4).

Regulatory T-cells develop primarily in the thymus (thymus-derived Tregs, tTregs), although they can also be differentiated in the periphery (peripherally-induced Tregs). The delineation of these two populations in the peripheral Treg compartment is difficult due to the lack of specific markers. Nevertheless, tTregs are thought to be enriched in self-reactive T-cell receptors (TCRs) and to be critical for the maintenance of self-tolerance [reviewed in Ref. (1)]. Despite extensive research on tTreg development using murine models in the past 20 years, many questions remain unanswered regarding the mechanisms involved in the establishment and maintenance of the tTreg lineage [reviewed in Ref. $(5,6)$ ]. Additionally, human tTreg studies are constrained by the limited number of tools available. Data have been mainly generated by in vitro manipulation of human thymic tissue or in vivo models using mouse/human chimeras [reviewed in Ref. (7)].

In this regard, the information provided by genetic human diseases characterized by thymusrelated disturbances, such as the DiGeorge, the Omenn, and the autoimmune polyendocrinopathy candidiasis ectodermal dystrophy (APECED) syndromes, have been instrumental [reviewed in 
Ref. $(8,9)]$. DiGeorge syndrome features athymia in $<1 \%$ of the patients, but in the majority of them the prevailing thymic hypoplasia is associated with mild to moderate T-cell lymphopenia, and increased incidence of infection and autoimmune diseases [reviewed in Ref. (10)]. Alterations in the circulating Treg compartment have been consistently reported in DiGeorge syndrome (11-13). Notably, a decreased proportion and number of FOXP3 ${ }^{+}$ cells in pediatric patients older than 2 years was observed when compared to age-matched healthy controls, in direct correlation with thymic output, as estimated by the numbers of $\mathrm{CD} 4^{+}$recent thymic emigrants (RTEs, defined by the expression of CD31 and CD45RA) (12). Omenn syndrome results from hypormorphic mutations in severe combined immunodeficiency (SCID)causing genes and is associated with the generation of a limited pool of T lymphocytes with a restricted repertoire and activated phenotype [reviewed in Ref. (8)]. Loss of corticomedullary junction and Hassall's bodies with depletion of autoimmune regulator gene (AIRE)-expressing medullary thymic epithelial cells (mTECs) and thymic dendritic cells (DCs) were described in two Omenn patients, in parallel with a dramatic decrease of Tregs in the thymus (14), supporting a role of AIRE-expressing mTEC and/or thymic DCs in their differentiation. In agreement, loss-offunction mutations in the AIRE gene (APECED syndrome) have been linked to a defective circulating Treg compartment (15-17). Not only is the frequency of naïve/resting Tregs (defined as CD4 ${ }^{+} \mathrm{FOXP} 3{ }^{+} \mathrm{CD} 45 \mathrm{RO}^{\text {neg }} \mathrm{CD} 31^{+}$) decreased in APECED patients but also their levels of FOXP3 expression, function, and repertoire are altered, further supporting an abnormal tTreg development in the absence of AIRE (16).

A recent study that involved a paired analysis of thymic and blood samples in young children (newborns to 1-year-old) showed a direct correlation between the size of the two Treg compartments, further supporting the importance of the thymus for the establishment of the peripheral Treg pool early in life (18). Of note, both human and murine RTEs are endowed with enhanced potential to convert into peripherally-induced Tregs, when compared to their more mature counterparts, implying an additional role of the thymus for the setting of the peripheral Treg compartment (19). Furthermore, patients with athymia due to complete DiGeorge or FOXN1 deficiency have been shown to recover the peripheral Treg compartment upon allogeneic thymus transplantation, irrespective of the degree of HLA mismatching (20-22).

It is vitally important to understand human tTreg development in order to devise strategies to manipulate their generation as well as their repertoire (23). This mini-review will provide an overview of the current knowledge regarding human tTreg development, as well as the fundamental questions that remain to be addressed.

\section{Commitment to the Treg Lineage: When?}

The human thymic primordium is colonized by T-cell progenitors during the 8 th week of gestation, but mature T-cells are only observed in the thymus at the 12th to 13th gestational weeks (24-26). At this stage, human tTregs can already be found in the thymus (27-29). The frequency of fetal human tTregs, identified by their elevated expression of the high-affinity IL-2 receptor alpha chain (IL-2R $\alpha / \mathrm{CD} 25$ ), was found to be stable throughout gestation (representing 6-7\% of total thymocytes) and similar to the proportion observed in infant thymuses (28).

Fetal human tTregs already express FOXP3, as assessed at the gene expression level, as well as other markers related to their suppressive phenotype, such as cytotoxic T-lymphocyte-associated protein 4 (CTLA-4) and glucocorticoid-induced TNFR-related protein (GITR) $(27,28)$. Moreover, these fetal human tTregs have the ability to suppress $\mathrm{T}$-cell proliferation $(27,28)$.

One question that has been extensively addressed in mice, but due to technical limitations only in a few human studies, is when and how a thymocyte becomes committed to the Treg lineage. The discrete populations that express Treg markers, such as CD25 and FOXP3, in the human post-natal thymus mainly comprise mature CD4 single-positive (CD4SP, $\left.\mathrm{CD} 4^{+} \mathrm{CD} 8^{\text {neg }}\right)$ thymocytes, but also include $\mathrm{CD} 8$ single-positive (CD8SP, CD $\left.4^{\text {neg }} \mathrm{CD} 8^{+}\right)$and double-positive (DP, $\left.\mathrm{CD} 4^{+} \mathrm{CD} 8^{+}\right)$thymocytes, as well as cells in early pre-DP stages $(27,28,30-36)$. In agreement, $\mathrm{FOXP}^{+} /$ $\mathrm{CD} 25^{+}$thymocytes can be found mostly in the medullary region of the human thymus, where mature thymocytes localize, with rare cells scattered in the cortex $(30,31,35,37,38)$. The mechanisms that allow for human tTreg commitment to occur are still ill-defined.

We and others have reported pre-DP expression of FOXP3, namely, at the triple-negative and CD4 immature single-positive stages $(33,35)$ (Table 1 ). However, the contribution of this population to the human tTreg pool remains to be addressed.

Double-positive thymocytes expressing FOXP3 and/or CD25 are clearly identified in the human thymus. They additionally express other Treg function-associated markers, such as CTLA-4, CD39, and GITR $(27,28,36)$, and exhibit suppressive function $(32,36)$ (Table 1). DP tTregs feature some degree of immaturity, as evidenced by the expression of recombinationactivating gene 2 mRNA (34). Moreover, upon stripping of surface molecules using pronase, DP tTregs re-acquire both CD4 and CD8 at the surface, confirming their bona-fide DP status (36). Nevertheless, the majority of human DP tTregs express high levels of CD3 and CD27, which are associated with positive selection and maturity $(27,36)$ (Table 1$)$. Importantly, DP tTregs are thought to significantly contribute to the CD4SP tTreg pool in humans, as predicted by linear regression models (36), and formally demonstrated by co-cultures of DP thymocytes with either TEC (36) or mature plasmacytoid (p)DCs (38). This observation contrasts with what has been described in murine models, where Foxp3 induction, although possible at the DP stage (45-47), mostly occurs at the CD4SP stage (48). Of note, human CD4SP CD2 $5^{\text {neg }}$ thymocytes are also permissive to FOXP3 acquisition $(37,39,49)$.

CD4SP tTreg represent the major population of FOXP3 ${ }^{+}$ human thymocytes. They phenotypically mirror peripheral Tregs and exhibit efficient regulatory function $(27,28,30,36$, 41, 43) (Table 1). The contribution of recirculating peripheral Tregs to this tTreg compartment is still debatable. It has long been proposed that activated T-cells may recirculate back to the thymus $(50,51)$, although this issue is particularly difficult to assess in humans. Recently, it was reported that a considerable proportion of human CD4SP tTregs may consist of recirculating 
TABLE 1 | Characterization of human post-natal thymic Tregs.

\begin{tabular}{llllll}
\hline Markers & Pre-DP & DP & CD4SP & CD8SP & Reference \\
\hline FOXP3 & + & +++ & +++ & ++ & $(31,33,35,36,39,40)$ \\
CD25 & - & +++ & +++ & ++ & $(30,31,33,35,36,39,41)$ \\
CTLA-4 & + & +++ & +++ & ++ & $(30,31,33,36,39,41,42)$ \\
CD127 & $-/+$ & + & - & - & $(33-36)$ \\
HLA-DR & ND & ++ & + & + & $(36)$ \\
CD39 & ND & ++ & ++ & + & $(36)$ \\
CD73 & ND & - & - & + & $(36)$ \\
CD103 & ND & + & - & ++ & $(36)$ \\
ICOS & ND & ++ & ++ & + & $(39,43,44)$ \\
CD69 & ND & ++ & ++ & + & $(34,36,42)$ \\
CD27 & ND & ++ & ++ & ++ & $(36,42)$ \\
Ki67 & + & + & $-/+$ & $-/+$ & $(36)$ \\
Suppressive & ND & Yes & Yes & Yes & $(30-32,36,39,41)$ \\
capacity & & & & &
\end{tabular}

$N D$, not determined.

cells (44). This was based on the observation that approximately one-fourth of these cells had lost CD31 and acquired ICOS and Tbet expression. Although it is not possible to exclude that a fraction of human tTregs may actually represent mature recirculating cells, there are some caveats to this interpretation. For instance, ICOS is already expressed by tTreg at the DP stage (39). Also, the high FOXP3 expression levels found within CD4SP ICOS ${ }^{+}$CD $31^{\text {neg }}$ tTregs (44) may reflect their interaction with ICOSL expressed on mTECs, as previously described (52). Moreover, TREC levels are reportedly comparable between the $\mathrm{CD} 4 \mathrm{SP} \mathrm{CD} 25^{+}$and CD25 ${ }^{\text {neg }}$ thymocyte populations, and several logs higher that those found in circulating Tregs, supporting that the majority of CD4SP tTregs are at the final stage of T-cell development (53). Of note, Vbeta usage and spectratyping analyses supported that CD4SP tTregs and CD4SP FOXP3 $3^{\text {neg }} /$ CD $25^{\text {neg }}$ thymocytes have a similarly diverse repertoire $(36,53)$. To our knowledge, the direct comparison of the thymic CD4SP FOXP3 ${ }^{+}$ and FOXP3 ${ }^{\text {neg }}$ repertoires has not been reported. Its assessment will be important to clarify this issue since in peripheral cells the Treg repertoire has only $24 \%$ overlap with conventional CD 4 T-cells (54). Additional studies will be instrumental in determining the magnitude and role of mature Treg recirculation in the human thymus.

Thus, tTreg lineage commitment may occur at various stages of human T-cell development.

\section{Commitment to the Treg Lineage: How?}

Studies in mice have clearly established the requirement for TCR stimulation in Treg lineage commitment [reviewed in Ref. $(5,6)]$. In humans, technical limitations preclude a direct assessment of the role of TCR signaling in tTreg development. We and others have shown that human tTreg differentiation is associated with markers of positive selection, such as CD69 and $\operatorname{CD} 27$ (27, 28, 34, 36, 42) (Table 1). Moreover, binding sites for the TCR downstream targets NFAT and AP1 are present within the human FOXP3 promoter that are directly activated by TCR stimulation (55). Notably, both DP and CD4SP tTreg express CTLA-4 $(30,36)$, a molecule that in mice was shown to be downstream of Nur77, an immediate early gene upregulated by TCR stimulation (56). Indirect evidence that enhanced TCR signaling strength may dictate thymocyte commitment into the Treg lineage can be further inferred by the increase in CD4SP $\mathrm{CD} 25^{+} \mathrm{FOXP}^{+}$thymocyte number in humanized mice treated with a superagonist anti-CD28 mAb (57). Moreover, human ZAP70-deficient patients present a dramatic decrease in the frequency and number of tTregs (58). Interestingly, CD4SP $\mathrm{CD} 25^{+}$tTregs were shown to frequently express two functional TCRs, in association with enhanced FOXP3 expression, suggesting that dual TCR expression may favor tTreg lineage commitment in humans (40). Overall, available evidence support that TCR signaling strength guides thymocyte commitment into the Treg lineage in humans, with a predicted impact on their self-reactivity.

Several additional signaling pathways and molecular factors have been implicated in human tTreg differentiation and/ or proliferation, namely JAK3/STAT-5, Notch, CD80/CD86, ICOS/ICOSL, CD40/CD40L, thymic stromal lymphopoietin (TSLP), as well as the common-gamma chain $(\gamma \mathrm{C})$ cytokines interleukin (IL)-2 and -15 (37-39, 49, 52, 59). Watanabe et al. demonstrated that TSLP from Hassall's bodies activate myeloid (m)DCs, enabling them to induce tTreg differentiation from CD4SP CD25 $5^{\text {neg }}$ thymocytes (37). pDCs are also capable of driving CD4SP non-regulatory thymocytes into the human Treg lineage, upon response to TSLP (49). Cognate interactions between $\mathrm{mDCs}$ or $\mathrm{pDCs}$ and CD4SP non-regulatory thymocytes are required, as differentiation was impaired by HLA-DR blockade $(37,49)$. Activation of pDCs with anti-CD40L and IL-3 also confers on them the capacity to differentiate postselection DP CD69 ${ }^{\text {hi TCR }}{ }^{\text {hi }}$ thymocytes into human tTregs (38). Additionally, mTECs were shown to promote the survival and proliferation of human tTregs in an ICOSL-dependent mechanism that required the presence of conventional CD4SP cells as source of IL-2 (52). We have recently investigated the requirement of $\gamma \mathrm{C}$ cytokines in human tTreg development and established a critical role for both IL-2 and IL-15 in their lineage commitment, as well as in tTreg proliferation and survival post-selection (39). This study also allowed the identification of macrophages and B lymphocytes as main IL-15 producers that likely represent two additional thymic antigen-presenting cell populations involved in human tTreg differentiation (39). In agreement, we found $\mathrm{FOXP}^{+}$cells in close vicinity of both macrophages and B cells in the human thymus (39). Accordingly, B lymphocytes were recently shown to be capable of selecting tTreg in mice $(60,61)$, and the majority of human CD4SP tTregs were shown to express CCR8 endowing them with the capacity to migrate in response to chemokines produced by macrophages (30).

As illustrated in Figure 1, the most immature thymocyte population that clearly expresses FOXP3, in addition to other Treg function-associated markers, such as CD25, CTLA-4, and CD39, and displays regulatory function is the cortical positively selected DP population $(27,28,36)$. The thymic cellular populations and signals mediating their positive selection and concomitant recruitment to the Treg lineage may include cortical TECs and macrophages, as well as IL-2/IL-15, shown by immunohistochemistry to be expressed in the human thymic 


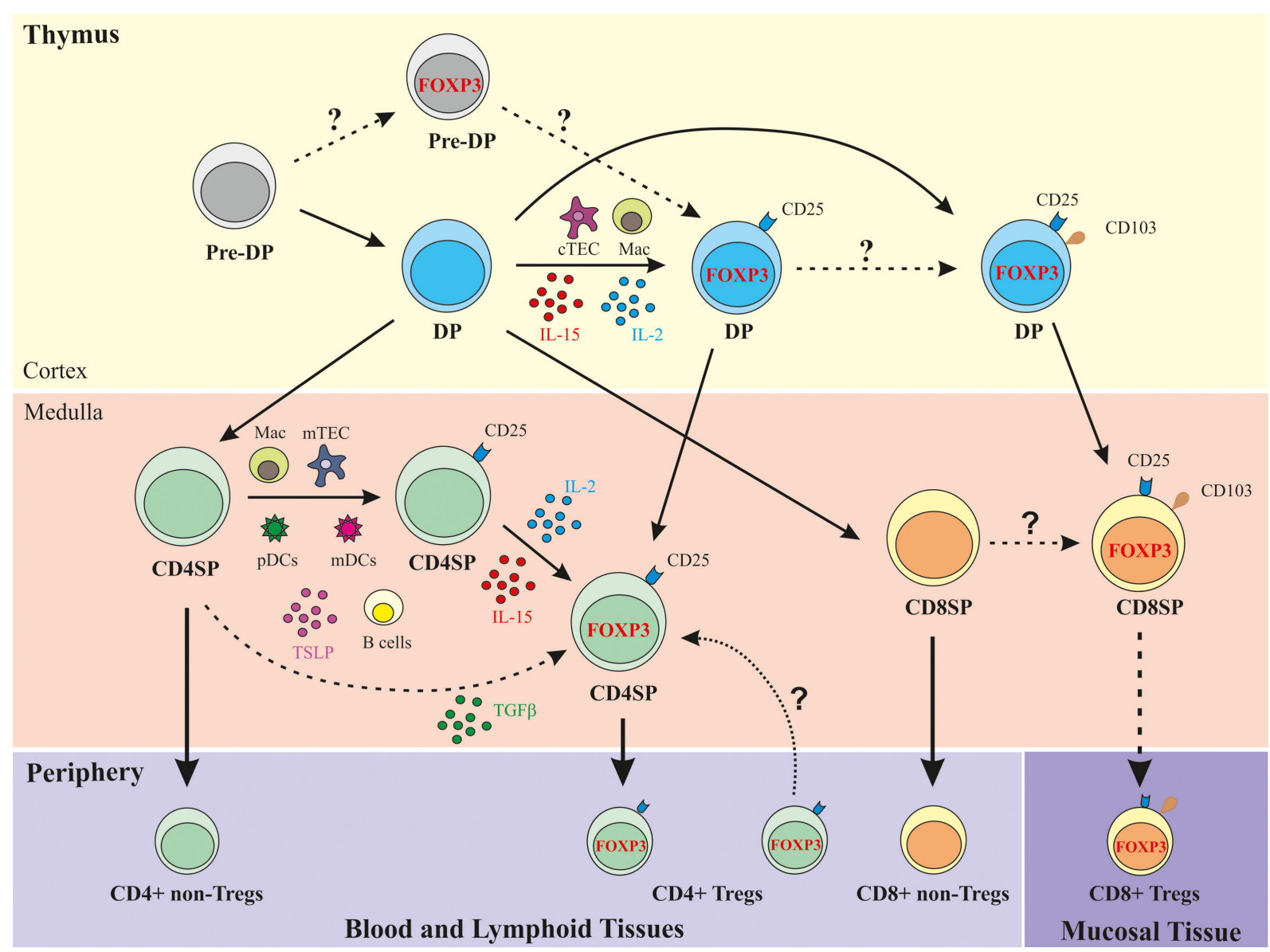

FIGURE 1 | Schematic representation of human Treg development in the human thymus. DP, double-positive $\left(\mathrm{CD} 4^{+} \mathrm{CD} 8^{+}\right)$; $\mathrm{CD} 4 \mathrm{SP}$, CD4 single-positive (CD4+CD8 $\left.{ }^{\text {neg }}\right)$; CD8SP, CD8 single-positive
$\left(C D 8{ }^{+} C D 4^{\text {neg }}\right)$; $C T E C$, cortical thymic epithelial cell; mTEC, medullary TEC; Mac, macrophage; FOXP3, Forkhead box P3; TSLP, thymic stromal lymphopoietin. cortex (39). The DP FOXP3 ${ }^{+}$thymocyte compartment directly correlates with the CD4SP FOXP3 ${ }^{+}$subset, denoting a precursor-product relationship (36). Upon interaction with activated pDCs, post-selection DP FOXP3 ${ }^{\text {neg }}$ cells may also differentiate into Tregs, in a costimulation-dependent manner (38). Medullary CD4SP FOXP $3^{\text {neg }}$ thymocytes can also acquire FOXP3 expression upon cognate interaction with activated pDCs or mDCs, in a costimulation- and IL-2-dependent fashion $(37,49)$. In addition, CD4SP FOXP3 ${ }^{\text {neg }}$ thymocytes may receive appropriate TCR and costimulation signals leading to CD25 acquisition and differentiation into tTreg precursors (CD4SP CD $25^{+} \mathrm{FOXP} 3^{\text {neg }}$ cells) (39). These precursors can differentiate into tTregs upon exposure to IL-2, produced mostly by cycling mature CD4SP thymocytes, or IL-15 secreted by macrophages, B lymphocytes, or mTECs (39). Whether concomitant TCR, costimulation, and $\gamma \mathrm{C}$ cytokine signaling also commits medullary CD4SP FOXP3 ${ }^{\text {neg }}$ thymocytes into tTregs, is a possibility remaining to be addressed. Finally, CD4SP CD25 $5^{\text {neg }}$ FOXP3 $3^{\text {neg }}$ thymocytes TCR-stimulated in the presence of costimulation, TGF- $\beta$ and IL-2/IL-15 signaling can also acquire FOXP3 expression and differentiate into CD4SP tTreg $(19,39)$.

\section{The Unique Properties of Human CD8SP tTregs}

In addition to the CD4SP human tTregs, a CD8SP population with phenotypic and functional Treg characteristics is present in the human thymus. CD8SP human tTregs express several Tregassociated markers, such as FOXP3, CD25, CTLA-4, and GITR, although at lower levels than CD4SP tTregs $(31,36)$ (Table 1). Similarly to CD4SP tTregs, they express very low levels of the IL-7 R $\alpha /$ CD127 molecule (36), and are able to suppress CD4SP CD25 ${ }^{\text {neg }}$ cells in a contact-dependent manner (31) (Table 1). A microRNA "signature" of CD8 Tregs has been recently defined in cord blood CD8 Treg (62).

Importantly, CD8SP human tTregs were found to express the $\alpha_{\mathrm{E}}$ chain (CD103) of the $\alpha_{\mathrm{E}} \beta_{7}$ integrin (36), a marker associated with CD4 Tregs in the periphery (63). CD103 was also expressed at the DP stage but was very low within CD4SP thymocytes, supporting a precursor-product relationship between $\mathrm{CD}_{103}{ }^{+} \mathrm{DP}$ and CD8SP human tTregs (36) (Table 1; Figure 1).

The role of CD103 expression on CD8SP FOXP3 ${ }^{+}$thymocytes remains to be addressed. High expression of E-cadherin, the 
main ligand of CD103, on mTEC (64) may promote retention of CD8 tTregs in the thymic medulla. Furthermore, in an in vitro cell adhesion assay, TEC-induced proliferation of CD8SP human thymocytes was inhibited by antibodies against E-cadherin or CD103, supporting a role for CD103 in CD8SP proliferation (64). Although the proliferation of CD8SP CD $25^{+}$thymocytes was not addressed in this setting, the higher levels of the active cell-cycle marker Ki67 found within CD8SP FOXP3 ${ }^{+}$as compared to CD8SP FOXP3 ${ }^{\text {neg }}$ thymocytes (36) also support this hypothesis.

Despite the low frequency of $\mathrm{CD}^{+}$Treg in the steady state, they may be of special relevance in pathologic conditions [reviewed in Ref. $(65,66)]$. CD103 has been associated with T-cell migration to mucosal sites $(67,68)$. In agreement, in the setting of colorectal cancer, $\mathrm{CD} 8^{+} \mathrm{FOXP} 3^{+} \mathrm{CD} 25^{+} \mathrm{T}$-cells were significantly increased in peripheral blood and in colorectal cancer tissue, indicating that these cells may contribute to tumor immune escape and disease progression (69). In addition, studies in macaques have described a rapid expansion of $\mathrm{CD} 8{ }^{+} \mathrm{FOXP} 3^{+} \mathrm{CD} 25^{+}$Tregs in the blood and colorectal mucosa following pathogenic SIV infection (70). An increase in the frequency of $\mathrm{CD}^{+}$Tregs has also been reported in HIV-1-infected patients (70).

In conclusion, a population of $\mathrm{CD}^{+}$Tregs is generated in the human thymus. A subset of post-selection DP FOXP3 ${ }^{+}$thymocytes expresses the tissue homing-associated molecule CD103, likely giving rise to the CD8SP $\mathrm{FOXP}^{+} \mathrm{CD}_{103}{ }^{+}$cells found in the medulla (Figure 1) (36). This finding supports the possibility that $\mathrm{CD}^{+}$Tregs egress the thymus expressing markers associated with mucosal homing, which may explain their very low frequency in the blood.

\section{References}

1. Sakaguchi S, Miyara M, Constantino CM, Hafler DA. FOXP3+ regulatory $\mathrm{T}$ cells in the human immune system. Nat Rev Immunol (2010) 10:490-500. doi:10.1038/nri2785

2. Bennett CL, Christie J, Ramsdell F, Brunkow ME, Ferguson PJ, Whitesell L, et al. The immune dysregulation, polyendocrinopathy, enteropathy, X-linked syndrome (IPEX) is caused by mutations of FOXP3. Nat Genet (2001) 27:20-1. doi: $10.1038 / 83713$

3. Wildin RS, Ramsdell F, Peake J, Faravelli F, Casanova JL, Buist N, et al. X-linked neonatal diabetes mellitus, enteropathy and endocrinopathy syndrome is the human equivalent of mouse scurfy. Nat Genet (2001) 27:18-20. doi:10.1038/83707

4. Seidel MG, Fritsch G, Lion T, Jurgens B, Heitger A, Bacchetta R, et al. Selective engraftment of donor CD4+25high FOXP3-positive T cells in IPEX syndrome after nonmyeloablative hematopoietic stem cell transplantation. Blood (2009) 113:5689-91. doi:10.1182/blood-2009-02-206359

5. Josefowicz SZ, Lu LF, Rudensky AY. Regulatory T Cells: mechanisms of differentiation and function. Annu Rev Immunol (2012) 30:531-64. doi:10.1146/ annurev.immunol.25.022106.141623

6. Hsieh CS, Lee HM, Lio CW. Selection of regulatory T cells in the thymus. Nat Rev Immunol (2012) 12:157-67. doi:10.1038/nri3155

7. Legrand N, Weijer K, Spits H. Experimental models to study development and function of the human immune system in vivo. J Immunol (2006) 176:2053-8. doi:10.4049/jimmunol.176.4.2053

8. Notarangelo LD. Combined immunodeficiencies with nonfunctional T lymphocytes. Adv Immunol (2014) 121:121-90. doi:10.1016/B978-0-12-800100-4. 00004-0

9. Pignata C, D’Assante R, Sousa AE. Thymic stromal alterations and genetic disorders of immune system. Front Immunol (2015) 6:81. doi:10.3389/ fimmu.2015.00081

\section{Concluding Remarks}

Cumulative evidence supports the existence of different pathways of Treg commitment in the human thymus that may occur at different stages of thymocyte differentiation. Their physiological contribution and the possible implications for the tTreg repertoire diversity remain unclear.

Thymus-derived Treg development does not seem to require a dedicated antigen-presenting cell population, as studies indicate that TECs, $\mathrm{mDC}$, and $\mathrm{pDC}$, as well as macrophages and B cells may be involved in tTreg selection. Finally, despite the proposed role of TCR signaling strength in human tTreg commitment, it has become increasingly clear that $\gamma \mathrm{C}$ cytokines, particularly IL-2 and IL-15, are important mediators of lineage stabilization.

The thymus and specifically tTregs represent important therapeutic targets to manipulate tolerance in many clinical settings, namely autoimmune diseases, tumor immunity, and transplantation. Furthermore, their targeting is also critical to achieve full immunological reconstitution in primary and secondary immunodeficiencies and to decrease the morbidity associated with hematopoietic stem-cell transplantation. It is therefore of utmost importance to further investigate human tTreg development, in order to take full-advantage of the current development of immune-based therapies.

\section{Acknowledgments}

IC, HN-C, and RBF received scholarships from Fundação para a Ciência e a Tecnologia (FCT) cofinanced by Programa Operacional Ciência e Inovação 2010 (POCI2010).
10. Davies EG. Immunodeficiency in DiGeorge syndrome and options for treating cases with complete athymia. Front Immunol (2013) 4:322. doi:10.3389/ fimmu.2013.00322

11. Sullivan KE, McDonald-McGinn D, Zackai EH. CD4(+) CD25(+) T-cell production in healthy humans and in patients with thymic hypoplasia. Clin Diagn Lab Immunol (2002) 9:1129-31. doi:10.1128/CDLI.9.5.1129-1131.2002

12. McLean-Tooke A, Barge D, Spickett GP, Gennery AR. Immunologic defects in 22q11.2 deletion syndrome. JAllergy Clin Immunol (2008) 122:e-7.doi:10.1016/ j.jaci.2008.03.033

13. Klocperk A, Grecová J, Šišmová K, Kayserová J, Froňková E, Šedivá A. Helios expression in T-regulatory cells in patients with Di George syndrome. J Clin Immunol (2014) 34:864-70. doi:10.1007/s10875-014-0071-y

14. Poliani PL, Facchetti F, Ravanini M, Gennery AR, Villa A, Roifman CM, et al. Early defects in human T-cell development severely affect distribution and maturation of thymic stromal cells: possible implications for the pathophysiology of Omenn syndrome. Blood (2009) 114:105-8. doi:10.1182/ blood-2009-03-211029

15. Kekalainen E, Tuovinen H, Joensuu J, Gylling M, Franssila R, Pontynen N, et al. A defect of regulatory $\mathrm{T}$ cells in patients with autoimmune polyendocrinopathy-candidiasis-ectodermal dystrophy. J Immunol (2007) 178:1208-15. doi:10.4049/jimmunol.178.2.1208

16. Laakso SM, Laurinolli TT, Rossi LH, Lehtoviita A, Sairanen H, Perheentupa $\mathrm{J}$, et al. Regulatory $\mathrm{T}$ cell defect in APECED patients is associated with loss of naive FOXP3(+) precursors and impaired activated population. J Autoimmun (2010) 35:351-7. doi:10.1016/j.jaut.2010.07.008

17. Arstila TP, Jarva H. Human APECED; a sick thymus syndrome? Front Immunol (2013) 4:313. doi:10.3389/fimmu.2013.00313

18. Machnes-Maayan D, Lev A, Katz U, Mishali D, Vardi A, Simon AJ, et al. Insight into normal thymic activity by assessment of peripheral blood samples. Immunol Res (2015) 61:198-205. doi:10.1007/s12026-014-8558-4 
19. Paiva RS, Lino AC, Bergman ML, Caramalho I, Sousa AE, Zelenay S, et al. Recent thymic emigrants are the preferential precursors of regulatory $\mathrm{T}$ cells differentiated in the periphery. Proc Natl Acad Sci U S A (2013) 110:6494-9. doi:10.1073/pnas.1221955110

20. Markert ML, Marques JG, Neven B, Devlin BH, McCarthy EA, Chinn IK, et al. First use of thymus transplantation therapy for FOXN1 deficiency (nude/SCID): a report of 2 cases. Blood (2011) 117:688-96. doi:10.1182/ blood-2010-06-292490

21. Albuquerque AS, Marques JG, Silva SL, Ligeiro D, Devlin BH, Dutrieux J, et al. Human FOXN1-deficiency is associated with $\alpha \beta$ double-negative and FoxP3+ T-cell expansions that are distinctly modulated upon thymic transplantation. PLoS One (2012) 7:e37042. doi:10.1371/journal.pone.0037042.g005

22. Chinn IK, Milner JD, Scheinberg P, Douek DC, Markert ML. Thymus transplantation restores the repertoires of forkhead box protein 3 (FoxP3)+ and FoxP3 - T cells in complete DiGeorge anomaly. Clin Exp Immunol (2013) 173:140-9. doi: $10.1111 /$ cei.12088

23. Nunes-Cabaço H, Sousa AE. Repairing thymic function. Curr Opin Organ Transplant (2013) 18:363-8. doi:10.1097/MOT.0b013e3283615df9

24. Haynes BF, Heinly CS. Early human T cell development: analysis of the human thymus at the time of initial entry of hematopoietic stem cells into the fetal thymic microenvironment. J Exp Med (1995) 181:1445-58. doi:10.1084/ jem.181.4.1445

25. Farley AM, Morris LX, Vroegindeweij E, Depreter MLG, Vaidya H, Stenhouse FH, et al. Dynamics of thymus organogenesis and colonization in early human development. Development (2013) 140:2015-26. doi:10.1242/dev.087320

26. Haddad R, Guimiot F, Six E, Jourquin F, Setterblad N, Kahn E, et al. Dynamics of thymus-colonizing cells during human development. Immunity (2006) 24:217-30. doi:10.1016/j.immuni.2006.01.008

27. Cupedo T, Nagasawa M, Weijer K, Blom B, Spits H. Development and activation of regulatory T cells in the human fetus. Eur J Immunol (2005) 35:383-90. doi:10.1002/eji.200425763

28. Darrasse-Jèze G, Marodon G, Salomon BL, Catala M, Klatzmann D. Ontogeny of CD4+CD25+ regulatory/suppressor T cells in human fetuses. Blood (2005) 105:4715-21. doi:10.1182/blood-2004-10-4051

29. Michaelsson J, Mold JE, McCune JM, Nixon DF. Regulation of T cell responses in the developing human fetus. J Immunol (2006) 176:5741-8. doi:10.4049/ jimmunol.176.10.5741

30. Annunziato F, Cosmi L, Liotta F, Lazzeri E, Manetti R, Vanini V, et al. Phenotype, localization, and mechanism of suppression of CD4+CD25+ human thymocytes. J Exp Med (2002) 196:379-87. doi:10.1084/jem.20020110

31. Cosmi L, Liotta F, Lazzeri E, Francalanci M, Angeli R, Mazzinghi B, et al. Human CD8+CD25+ thymocytes share phenotypic and functional features with CD4+CD25+ regulatory thymocytes. Blood (2003) 102:4107-14. doi:10.1182/blood-2003-04-1320

32. Liotta F, Cosmi L, Romagnani P, Maggi E, Romagnani S, Annunziato F. Functional features of human CD25+ regulatory thymocytes. Microbes Infect (2005) 7:1017-22. doi:10.1016/j.micinf.2005.03.024

33. Tuovinen H, Kekäläinen E, Rossi LH, Puntila J, Arstila TP. Cutting edge: human CD4-CD8- thymocytes express FOXP3 in the absence of a TCR. J Immunol (2008) 180:3651-4. doi:10.4049/jimmunol.180.6.3651

34. Tuovinen H, Pekkarinen PT, Rossi LH, Mattila I, Arstila TP. The FOXP3+ subset of human CD4+CD8+ thymocytes is immature and subject to intrathymic selection. Immunol Cell Biol (2008) 86:523-9. doi:10.1038/icb.2008.36

35. Nunes-Cabaço H, Ribot JC, Caramalho Í, Serra-Caetano A, Silva-Santos B, Sousa AE. Foxp3 induction in human and murine thymus precedes the CD4+ CD8+ stage but requires early T-cell receptor expression. Immunol Cell Biol (2010) 88:523-8. doi:10.1038/icb.2010.4

36. Nunes-Cabaço H, Caramalho Í, Sepúlveda N, Sousa AE. Differentiation of human thymic regulatory T cells at the double positive stage. Eur J Immunol (2011) 41:3604-14. doi:10.1002/eji.201141614

37. Watanabe N, Wang YH, Lee HK, Ito T, Wang YH, Cao W, et al. Hassall's corpuscles instruct dendritic cells to induce CD4+CD25+ regulatory T cells in human thymus. Nature (2005) 436:1181-5. doi:10.1038/nature03886

38. Martin-Gayo E, Sierra-Filardi E, Corbi AL, Toribio ML. Plasmacytoid dendritic cells resident in human thymus drive natural Treg cell development. Blood (2010) 115:5366-75. doi:10.1182/blood-2009-10-248260

39. Caramalho Í, Nunes-Silva V, Pires AR, Mota C, Pinto AI, Nunes-Cabaço $\mathrm{H}$, et al. Human regulatory T-cell development is dictated by interleukin-2 and -15 expressed in a non-overlapping pattern in the thymus. $J$ Autoimmun (2015) 56:98-110. doi:10.1016/j.jaut.2014.11.002

40. Tuovinen H, Salminen JT, Arstila TP. Most human thymic and peripheral-blood CD4+CD25+ regulatory T cells express 2 T-cell receptors. Blood (2006) 108:4063-70. doi:10.1182/blood-2006-04-016105

41. Stephens LA, Mottet C, Mason D, Powrie F. Human CD4+ CD25+ thymocytes and peripheral $\mathrm{T}$ cells have immune suppressive activity in vitro. Eur J Immunol (2001) 31:1247-54. doi:10.1002/1521-4141(200104)31:4<1247:: AID-IMMU1247>3.0.CO;2-M

42. Wing K, Ekmark A, Karlsson H, Rudin A, Suri-Payer E. Characterization of human CD25+ CD4+ T cells in thymus, cord and adult blood. Immunology (2002) 106:190-9. doi:10.1046/j.1365-2567.2002.01412.x

43. Ito T, Hanabuchi S, Wang YH, Park WR, Arima K, Bover L, et al. Two functional subsets of FOXP3 + regulatory T cells in human thymus and periphery. Immunity (2008) 28:870-80. doi:10.1016/j.immuni.2008.03.018

44. Thiault N, Darrigues J, Adoue V, Gros M, Binet B, Perals C, et al. Peripheral regulatory $\mathrm{T}$ lymphocytes recirculating to the thymus suppress the development of their precursors. Nat Immunol (2015) 16:628-34. doi:10.1038/ni.3150

45. Cabarrocas J, Cassan C, Magnusson F, Piaggio E, Mars L, Derbinski J, et al. Foxp3+ CD25+ regulatory $\mathrm{T}$ cells specific for a neo-self-antigen develop at the double-positive thymic stage. Proc Natl Acad Sci U S A (2006) 103:8453-8. doi:10.1073/pnas.0603086103

46. Ribot J, Enault G, Pilipenko S, Huchenq A, Calise M, Hudrisier D, et al. Shaping of the autoreactive regulatory $\mathrm{T}$ cell repertoire by thymic cortical positive selection. J Immunol (2007) 179:6741-8. doi:10.4049/jimmunol.179.10.6741

47. Liston A, Nutsch KM, Farr AG, Lund JM, Rasmussen JP, Koni PA, et al. Differentiation of regulatory Foxp3 + T cells in the thymic cortex. Proc Natl Acad Sci U S A (2008) 105:11903-8. doi:10.1073/pnas.0801506105

48. LeeHM,Hsieh CS. Rare development of Foxp3+thymocytes in the CD4+CD8+ subset. J Immunol (2009) 183:2261-6. doi:10.4049/jimmunol.0901304

49. Hanabuchi S, Ito T, Park WR, Watanabe N, Shaw JL, Roman E, et al. Thymic stromal lymphopoietin-activated plasmacytoid dendritic cells induce the generation of FOXP3 + regulatory T cells in human thymus. J Immunol (2010) 184:2999-3007. doi:10.4049/jimmunol.0804106

50. Michie SA, Rouse RV. Traffic of mature lymphocytes into the mouse thymus. Thymus (1989) 13:141-8.

51. Kirberg J, Bosco N, Deloulme JC, Ceredig R, Agenès F. Peripheral T lymphocytes recirculating back into the thymus can mediate thymocyte positive selection. J Immunol (2008) 181:1207-14. doi:10.4049/jimmunol.181.2.1207

52. Nazzal D, Gradolatto A, Truffault F, Bismuth J, Berrih-Aknin S. Human thymus medullary epithelial cells promote regulatory T-cell generation by stimulating interleukin-2 production via ICOS ligand. Cell Death Dis (2014) 5:e1420. doi:10.1038/cddis.2014.377

53. Kasow KA, Chen XH, Knowles J, Wichlan D, Handgretinger R, Riberdy JM. Human CD4+CD25+ regulatory T cells share equally complex and comparable repertoires with CD4+CD25- counterparts. J Immunol (2004) 172:6123-8. doi:10.4049/jimmunol.172.10.6123

54. Fazilleau N, Bachelez H, Gougeon ML, Viguier M. Cutting edge: size and diversity of CD4+CD25high Foxp3+ regulatory $\mathrm{T}$ cell repertoire in humans: evidence for similarities and partial overlapping with CD4+CD25- T Cells. J Immunol (2007) 179:3412-6. doi:10.4049/jimmunol.179.6.3412

55. Mantel PY, Ouaked N, Ruckert B, Karagiannidis C, Welz R, Blaser K, et al. Molecular mechanisms underlying FOXP3 induction in human $\mathrm{T}$ cells. J Immunol (2006) 176:3593-602. doi:10.4049/jimmunol.176.6.3593

56. Rajpal A, Cho YA, Yelent B, Koza-Taylor PH, Li D, Chen E, et al. Transcriptional activation of known and novel apoptotic pathways by Nur77 orphan steroid receptor. EMBO J (2003) 22:6526-36. doi:10.1093/emboj/cdg620

57. Legrand N, Cupedo T, van Lent AU, Ebeli MJ, Weijer K, Hanke T, et al. Transient accumulation of human mature thymocytes and regulatory $\mathrm{T}$ cells with CD28 superagonist in "human immune system" Rag2-/-gammac-/- mice. Blood (2006) 108:238-45. doi:10.1182/blood-2006-01-0190

58. Poliani PL, Fontana E, Roifman CM, Notarangelo LD. $\zeta$ Chain-associated protein of $70 \mathrm{kDa}$ (ZAP70) deficiency in human subjects is associated with abnormalities of thymic stromal cells: implications for T-cell tolerance. J Allergy Clin Immunol (2013) 131:e-600. doi:10.1016/j.jaci.2012.11.002

59. Hutton JF, Gargett T, Sadlon TJ, Bresatz S, Brown CY, Zola H, et al. Development of CD4+CD25+FoxP3+ regulatory $\mathrm{T}$ cells from cord blood hematopoietic progenitor cells. J Leukoc Biol (2008) 85:445-51. doi:10.1189/jlb.1008620 
60. Walters SN, Webster KE, Daley S, Grey ST. A role for intrathymic B cells in the generation of natural regulatory T cells. J Immunol (2014) 193:170-6. doi:10.4049/jimmunol.1302519

61. Lu FT, Yang W, Wang YH, Ma HD, Tang W, Yang JB, et al. Thymic B cells promote thymus-derived regulatory $\mathrm{T}$ cell development and proliferation. J Autoimmun (2015) 61:62-72. doi:10.1016/j.jaut.2015.05.008

62. Jebbawi F, Fayyad-Kazan H, Merimi M, Lewalle P, Verougstraete JC, Leo O, et al. A microRNA profile of human $\mathrm{CD} 8(+)$ regulatory $\mathrm{T}$ cells and characterization of the effects of microRNAs on Treg cell-associated genes. J Transl Med (2014) 12:218. doi:10.1186/s12967-014-0218-X

63. Allakhverdi Z, Fitzpatrick D, Boisvert A, Baba N, Bouguermouh S, Sarfati M, et al. Expression of CD103 identifies human regulatory T-cell subsets. J Allergy Clin Immunol (2006) 118:1342-9. doi:10.1016/j.jaci.2006.07.034

64. Kutlesa S, Wessels JT, Speiser A, Steiert I, Müller CA, Klein G. E-cadherinmediated interactions of thymic epithelial cells with CD103+ thymocytes lead to enhanced thymocyte cell proliferation. J Cell Sci (2002) 115:4505-15. doi:10.1242/jcs.00142

65. Tang XL, Smith TR, Kumar V. Specific control of immunity by regulatory CD8 T cells. Cell Mol Immunol (2005) 2:11-19.

66. Kapp JA, Bucy RP. CD8+ suppressor T cells resurrected. Hum Immunol (2008) 69:715-20. doi:10.1016/j.humimm.2008.07.018

67. Cerf-Bensussan N, Jarry A, Brousse N, Lisowska-Grospierre B, Guy-Grand D, Griscelli C. A monoclonal antibody (HML-1) defining a novel membrane molecule present on human intestinal lymphocytes. Eur J Immunol (1987) 17:1279-85. doi:10.1002/eji.1830170910

68. Cepek KL, Parker CM, Madara JL, Brenner MB. Integrin alpha E beta 7 mediates adhesion of T lymphocytes to epithelial cells. J Immunol (1993) 150:3459-70.

69. Chaput N, Louafi S, Bardier A, Charlotte F, Vaillant JC, Menegaux F, et al. Identification of CD8+CD25+Foxp3+ suppressive T cells in colorectal cancer tissue. Gut (2009) 58:520-9. doi:10.1136/gut.2008.158824

70. Nigam P, Velu V, Kannanganat S, Chennareddi L, Kwa S, Siddiqui M, et al. Expansion of FOXP3+ CD8 T cells with suppressive potential in colorectal mucosa following a pathogenic simian immunodeficiency virus infection correlates with diminished antiviral T cell response and viral control. J Immunol (2010) 184:1690-701. doi:10.4049/jimmunol.0902955

Conflict of Interest Statement: The authors declare that the research was conducted in the absence of any commercial or financial relationships that could be construed as a potential conflict of interest.

Copyright $₫ 2015$ Caramalho, Nunes-Cabaço, Foxall and Sousa. This is an open-access article distributed under the terms of the Creative Commons Attribution License (CC BY). The use, distribution or reproduction in other forums is permitted, provided the original author(s) or licensor are credited and that the original publication in this journal is cited, in accordance with accepted academic practice. No use, distribution or reproduction is permitted which does not comply with these terms. 